Working Paper 2010:16

Department of Economics

\title{
Measuring sustainability under regime shift uncertainty: A resilience pricing approach
}

Karl-Göran Mäler and Chuan-Zhong Li 
Department of Economics

Uppsala University

P.O. Box 513

SE-751 20 Uppsala

Sweden

Fax: +4618471 1478
Working paper 2010:16

August 2010

ISSN 1653-6975

MeAsuring SUSTAINABILITY UNDER REGIME SHIFT UNCERTAINTY: A RESILIENCE PRICING APPROACH Karl-Göran Mäler and Chuan-Zhong LI

Papers in the Working Paper Series are published on internet in PDF formats.

Download from http://www.nek.uu.se or from S-WoPEC http://swopec.hhs.se/uunewp/ 


\title{
Measuring sustainability under regime shift uncertainty: A resilience pricing approach
}

\author{
Karl-Göran Mäler and Chuan-Zhong Li*
}

July 2,2010

\begin{abstract}
This paper is concerned with the theory of resilience pricing and sustainability measurement in the presence of risk for regime shift in a dynamic economy-environment system. Following Holling (1973), we consider resilience as the maximal perturbation that the system can absorb without flipping into a qualitatively different state. Using a multisector growth model under uncertainty, we derive the shadow price of resilience that affects the probabilities of the system to flip in the future. We also analyze the role of resilience on sustainability with both ex-ante and ex-post welfare measures.
\end{abstract}

JEL: D6, D9, Q5

Keywords: Regime shift, resilience, ecosystem, valuation, and inclusive wealth.

*Karl-Göran Mäler, the Beijer Institute, KVA, and Chuan-Zhong Li, Department of Economics, Uppsala University. The authors thank John Tschirhart, Xueqin Zhu and the participants at the Fourth World Congress of Environmental and Resource Economists, Montreal, Canada, for valuable comments and suggestions. 


\section{Introduction}

It is well-known nowadays that wealth is the appropriate indicator of whether or not an economy is on a sustainable development path. To the best of our knowledge, it was Samuelson (1961) who first understood this in the context of an optimal economy. In several recent papers, Dasgupta and Mäler (2000), Arrow et al. (2003) and Mäler et al. (2008) developed the theory even for non-optimal economies and showed that changes in wealth over time are a nearly perfect welfare indicator. However, it was Pearce et al. (1989) and Pearce and Atkinson (1993) who first applied the concept empirically. It is worth mentioning that wealth as welfare indicator needs to be understood and measured as a comprehensive concept including nonmarket goods and services such as human capital and ecosystem services.

This paper shows how ecosystem resilience can be included in the comprehensive wealth measurements framework. In all ecosystems, there are feedbacks between different components. Some of these feedbacks are positive, which implies that an initial perturbation of the system will be amplified. Sometimes, the positive feedback becomes active when the system reaches a particular state, and the result is that the system will flip into a different state which may be very different from the initial state (cf. Norton, 1995; Ekins et al., 2003; Gunderson, 2001; Scheffer et al., 2001). The state has then a threshold or a bifurcation. If the initial state is judged to be better than the state the system would reach if it would switch, it is of importance to prevent it from reaching the threshold. The largest perturbation the system can absorb without flipping into a different state is known as resilience (Holling 1973).

If there is no uncertainty about the dynamics of the system, we can always manage the system to stay within the bounds of resilience. However, we never have full information and it is better to regard the system as a stochastic process (Perrings, 2006). This implies that there may be a positive proba- 
bility that the system will reach the threshold and flip into the non-desired state. This probability will be lower if the resilience increases. Therefore it is essential to manage the resilience. Furthermore, resilience should be regarded as a capital stock as it provides us with a kind of insurance against reaching a non-desired state.

As a stock, resilience has an accounting price and that price corresponds to the change in the expected net present value of future ecosystem services resulting from a marginal increase in resilience stock today (Mäler et al., 2007). Thus, we can estimate the accounting price if we know the dynamics of the system and the statistics of the system (as a stochastic process). This idea has been applied in a case study of the Goulburn-Broken Catchment in South East Australia (Walker et al., 2010) where the resilience stock in this system is the distance of the current water table to its threshold level at which the normal agricultural land would flip into a salinized state.

In this paper, we attempt to further develop the resilience pricing model in Mäler et al. (2007) and Walker et al. (2010) in several new directions. In sections 2 and 3 , we generalize the original model for pricing an initial resilience stock to pricing resilience at any future date through the use of integrated hazard functions. We also explore the properties of resilience prices such as their algebraic signs and the relationship with the existing resilience stock. In section 4, we examine the implication of resilience prices for ex-ante and ex-post welfare measurement. As compared to the ex-post case, it is shown that the ex-ante measure of comprehensive wealth growth involves two extra terms in addition to the usual genuine saving expression. One is the expected loss due to the future flip risk and the other is the risk aversion loss due to the uncertain resilience stock change in a future period. Section 5 sums up the paper. 


\section{$2 \quad$ A prototype model}

Consider an economy-environment system with conventional capital stocks $\mathbf{K}(t)$ such as physical capital, natural and environmental assets at time $t$, with initial values $\mathbf{K}(0)=\mathbf{K}_{0}>\mathbf{0}$. In addition, there is a resilience-related stock $Z(t)$ with initial stock $Z(0)=Z_{0}$. We assume two possible regimes, a normal regime with the resilience-related stock $Z(t)$ greater than its threshold value $\tilde{Z}(t)$ i.e. $Z(t)>\tilde{Z}(t)$, and a disturbed regime after a flip in the ecological system with $Z(t)<\tilde{Z}(t)$. Following Holling, we define $X(t)=$ $Z(t)-\tilde{Z}(t)$ as a resilience stock which corresponds to the maximum disturbance the system can absorb without flipping from the normal into a disturbed state. To start with, we assume that $Z(t)$ is a resilience-related stock following some "pure" stochastic process without any active management and $\tilde{Z}(t)$ is a deterministic threshold value. The stock $X(t)$ in this setting is thus a "pure" resilience stock with no direct contribution to the economy $^{1}$ but an indirect effect through its effect on the risk of regime shift. Later on, we will extend the model with resilience management. Initially, we have the normal regime such that $Z(0)>\tilde{Z}(t)$ or $X_{0}>0$. As time goes, however, there is a probability at each point in time $t$ such that the system flips from the normal into a disturbed regime. The flip probabilities over time will of course depend on the properties of the underlying stochastic process $X(t)=f\left(X_{0}, t, \varepsilon\right)$ where $\varepsilon$ is some stochastic component.

For the moment, let us simply assume that the probability density for a flip at time $s>0$, from the normal regime into a disturbed one, be $\theta\left(X_{0}, s\right)$. The cumulative flip probability over a time interval $[0, t]$, then, becomes $F\left(X_{0}, t\right)=\int_{0}^{t} \theta\left(X_{0}, s\right) d s$, with properties $F\left(X_{0}, 0\right)=0$ and $\lim _{t \rightarrow \infty} F\left(X_{0}, t\right)=$ 1. The corresponding probability for the normal regime to survive over the time interval $[0, t]$, conditional on a normal regime at the initial date $t=0$

\footnotetext{
${ }^{1}$ If the same stock has other functions than the resilience service, then it can be treated as a composite stock with partial contribution to resilience services.
} 
can be expressed as $S\left(X_{0}, t\right)=1-F\left(X_{0}, t\right)$. With a given stream of flip risks, we will first derive an expression for the expected intertemporal welfare, and then study the implicit price of the resilience stock. Conditional on the normal regime, a governing rule $\alpha_{1}$ as defined in Arrow et al. (2003) would map the initial condition $\mathbf{K}_{0}$ into a stream of vector-valued consumption services $\mathbf{C}_{1}(t)$ and capital stocks $\mathbf{K}_{1}(t)$ such that $\mathbf{C}_{1}(t)=\mathbf{F}\left(\mathbf{K}_{0}, \alpha_{1}, t\right)$ and $\mathbf{K}_{1}(t)=\mathbf{G}\left(\mathbf{K}_{0}, \alpha_{1}, t\right), t \in[0, \infty)$, where $\mathbf{F}$ and $\mathbf{G}$ are two different vectorvalued functions. If the system flips at time $s \in[0, \infty)$ with a structural change, then consumption and capital henceforth would follow an alternative path governed by an adapted rule $\alpha_{2}$ such that $\mathbf{C}_{2}(t)=\mathbf{F}\left(\mathbf{K}(s), \alpha_{2}, t-s\right)$ and $\mathbf{K}_{2}(t)=\mathbf{G}\left(\mathbf{K}(s), \alpha_{2}, t-s\right)$ for $t \in[s, \infty)$. Note that the governance rules may also be optimal rules in a first best setting with perfect governance.

Preferences are represented by a time-invariant utility function $V(\mathbf{C}(t))$, which satisfies certain regularity conditions. For notational ease, we denote the instantaneous utility at time $t$ conditional on the normal regime by $U_{1}(t)=V\left(\mathbf{C}_{1}(t)\right)$, and that conditional on the disturbed regime by $U_{2}(t)=V\left(\mathbf{C}_{2}(t)\right)$ for all $t \in[0, \infty)$.

Imagine that the system flips at a known date $s$, then the intertemporal welfare would be

$$
\left.W_{0}(s)=\int_{0}^{s} U_{1}(t) \exp (-r t)\right) d t+\int_{s}^{\infty} U_{2}(t) \exp (-r t) d t
$$

where $r$ denotes the rate of pure time preference ${ }^{2}$. For a stochastic flipping date, the expected intertemporal welfare can be expressed by

$$
E\left(W_{0}\right)=\int_{0}^{\infty} \theta\left(X_{0}, s\right) W_{0}(s) d s=\int_{0}^{\infty} W_{0}(s) d F\left(X_{0}, s\right)
$$

\footnotetext{
${ }^{2}$ Barbier and Strand (1998) published a model very similar to the one presented in this paperr. The difference is in the purpose of modelling. Here we are interested in the inclusion of resilience values in the accounts of wealth, while Barbier and Strand were interested in cost benefit analysis of changes in the mangrove forest.
} 
Integrating (2) by parts and making use of (1), we obtain the expected intertemporal welfare

$$
\begin{aligned}
E\left(W_{0}\right) & =\left.W_{0}(s) F\left(X_{0}, s\right)\right|_{0} ^{\infty}-\int_{0}^{\infty} F\left(X_{0}, s\right)\left[U_{1}(s)-U_{2}(s)\right] \exp (-r s) d s \\
& =\int_{0}^{\infty} U_{1}(s) \exp (-r s) d s-\int_{0}^{\infty} F\left(X_{0}, s\right)\left[U_{1}(s)-U_{2}(s)\right] \exp (-r s) d s
\end{aligned}
$$

where the second equality follows from the properties of cumulative distribution function $F\left(X_{0}, s\right)$ and the finiteness of the utility function ${ }^{3}$. While the first integral on the second line of (3) represents the "normal" wealth, the second integral measures the expected loss in welfare due to the risk of a future flip. An alternative expression of (3) is

$$
E\left(W_{0}\right)=\int_{0}^{\infty}\left[S\left(X_{0}, s\right) U_{1}(s)+F\left(X_{0}, s\right) U_{2}(s)\right] \exp (-r s) d s
$$

where $S\left(X_{0}, s\right)=1-F\left(X_{0}, s\right)$ denotes the survival probability of the normal regime from time 0 to $s$. The expression (4) corresponds to the present discounted value of future expected utilities i.e. the weighted average of two extreme utility streams, one is the ideal normal stream and the other is the fully disturbed utility one. Note that we have converted the expression (1) involving two subsequent time periods to a linear combination of two parallel streams in (4) due to the stochastic flip date.

Now, what is the shadow price of the resilience stock $X_{0}$ at the initial date? By applying the Leibniz rule, we obtain the following expression

$$
q(0)=\frac{\partial E\left(W_{0}\right)}{\partial X_{0}}=-\int_{0}^{\infty} \frac{\partial F\left(X_{0}, s\right)}{\partial X_{0}}\left[U_{1}(s)-U_{2}(s)\right] \exp (-r s) d s
$$

\footnotetext{
${ }^{3}$ This model is similar to the catastrophe model developed by Cropper (1976) though the intended application is different.
} 
This is the marginal contribution of an extra unit of the resilience stock to the intertemporal welfare i.e. the expected present value of future utilities. If the resilience stock is defined in a positive way such that $X_{0}$ is a public "good" rather than "bad", then we expect its price $q(0)$ to be positive. Suppose that the normal regime we have now is a desirable regime and the flipped regime is an undesirable one. Then, we have $\int_{0}^{\infty}\left[U_{1}(s)-U_{2}(s)\right] \exp (-r s) d s>0$ i.e. the present value of future utilities is larger under the normal regime than the disturbed one, though it is possible for $U_{1}(s)-U_{2}(s)<0$ at some points in time $s$. In addition, we should also have $\partial F\left(X_{0}, s\right) / \partial X_{0}<0$ i.e. a higher initial resilience stock contributes to lower future flip probabilities. Then we state the following proposition:

Proposition 1 Suppose that the initial resilience stock $X_{0}$ is defined in a positive way such that $\int_{0}^{\infty}\left[U_{1}(s)-U_{2}(s)\right] \exp (-r s) d s>0$ and $\partial F\left(X_{0}, s\right) / \partial X_{0}<$ 0 for all $s \in[0, \infty)$, then the resilience price in (5) is positive with $q(0)>0$.

Proof. The proof is straightforward. Let $m=\inf _{s}\left(-\frac{\partial F\left(X_{0}, s\right)}{\partial X_{0}}\right)>0$, then $q(0)=-\int_{0}^{\infty} \frac{\partial F\left(X_{0}, s\right)}{\partial X_{0}} \Delta U(s) \exp (-r s) d s>m \int_{0}^{\infty} \Delta U(s) \exp (-r s) d s>0$, where $\Delta U(s)=U_{1}(s)-U_{2}(s)$.

It is worth mentioning that whether a regime is desirable or not is an economic question depending on human preferences rather than pure ecological issues (cf. Nelson et al., 2007). There might exist rather resilient systems in a "normal" or current regime (cf. Max et al., 2004) such as an algae-dominated lake ecosystem which can greatly resist to changes but the regime is less desirable than a fish-dominated one where $\int_{0}^{\infty} \Delta U(s) \exp (-r s) d s<0$. In such a case, the resilience price would be negative as the alternative regime would be better. Note also that even if resilience is a "good", its marginal value may not follow the typical downward-sloping trend with respect to the existing resilience stock level. The intuition is that for a highly resilient system, the effect of an extra unit of the resilience stock on the flip probability may 
be small but the expected present discounted value of future utilities may be large. On the other hand, if a system is less resilient, then the present value of future utilities would be low but an extra resilience stock in this case may have a larger effect on the reduction of the flip probabilities.

\section{$3 \quad$ Flip modeling and resilience pricing}

This section describes how the cumulative flip probability $F\left(X_{0}, s\right)$ and thereby the survival probability $S\left(X_{0}, s\right)$ are associated with the stochastic process $X(t)$ for $t \geq 0$. Initially, we have $X_{0}>0$ i.e. $Z(0)>\tilde{Z}(0)$ in the normal regime. As time goes, the stochastic variable $Z(t)$ fluctuates and the probability for the system to flip over a short time period $[t, t+d t]$, conditional on survival up to time $t$, is

$$
\operatorname{Pr}(X(t) \leq 0)=\operatorname{Pr}(Z(t) \leq \tilde{Z}(t))=G_{t}(\tilde{Z}(t))
$$

where $G_{t}(\cdot)$ denotes the "in-space" cumulative probability function at time $t$, valid for the infinitesimal time interval $[t, t+d t]$. The lower the resilience stock $X(t)=Z(t)-\tilde{Z}(t)$ is, the larger probability the system would flip. Along the "time" dimension, this can also be seen as the hazard rate at time $t$ i.e.,

$$
\lambda(t) \equiv G_{t}(\tilde{Z}(t))
$$

The survival probability over $[t, t+d t]$, conditional on a survival up to time $t$, can thus be expressed as

$$
1-\lambda(t) d t \approx \exp (-\lambda(t) d t)
$$

for $d t \rightarrow 0$. This can be readily verified by a first-order Taylor expansion of the exponential function $\exp (-\lambda(t) d t)$ at $d t=0$. While the discrete version of the total survival probability from time 0 to $\eta$ is given by $\Pi_{n=1}^{m}\left(1-\lambda\left(t_{n}\right) d t\right)$ with $t_{1}=0, t_{n+1}=t_{n}+d t, t_{m}=\eta, n=1,2, \ldots, m$, the corresponding 
continuous time version of the survival probability function from time 0 to $t$, conditional on the initial resilience stock $X_{0}$, becomes

$$
S\left(X_{0}, t\right)=\exp \left(-\int_{0}^{t} \exp (\lambda(s) d s)\right)=\exp (-\Lambda(t))
$$

where $\Lambda(t)=\int_{0}^{t} \exp (\lambda(s) d s)$ denotes the integrated hazard function. The cumulative probability distribution function for a flip up to time $t$ is thus $F\left(X_{0}, t\right)=1-S\left(X_{0}, t\right)$.

It is seen that while the cumulative distribution function $G_{t}(\cdot)$ in $(6)$ is defined over "space" for the resilience stock at a given point in time $t$, the cumulative distribution function, $F\left(X_{0}, t\right)$, is defined over "time" for $[0, t]$. We will now show how the two different cumulative distribution functions are related to each other. Since $1-F\left(X_{0}, t\right)=\exp (-\Lambda(t))$, we can take the time derivative on both hand-sides to obtain

$$
\theta\left(X_{0}, t\right)=\lambda(t) \exp (-\Lambda(t))
$$

and then integrate the density function over time to obtain

$$
F\left(X_{0}, t\right)=\int_{0}^{t} \lambda(s) \exp (-\Lambda(s)) d s
$$

To get a better feel about the relationships, consider a constant hazard rate $\lambda(s)=\bar{\lambda}$ with integrated hazard $\Lambda(s)=\exp (\bar{\lambda} s)$. Then, the flip probability would follow an exponential form $\theta\left(X_{0}, s\right)=\bar{\lambda} \exp (-\bar{\lambda} s)$, and the survival probability is given by the well-known form $S\left(X_{0}, s\right)=\exp (-\bar{\lambda} s)$. In practice, however, the hazard rate may change over time depending on the type of ecosystems and the underlying stochastic process of the resilience stock. In this paper, we assume an autonomous stochastic process for a stylized ecosystem (cf. Dixit and Pindyck, 1994)

$$
d X(s-t)=a(X) d(s-t)+b(X) d w(s-t), X(t)=X_{t}, s \geq t \text { and } t \geq 0
$$

i.e. an generalized Ito process with $d w(s-t)=\varepsilon \sqrt{d(s-t)}$, where $\varepsilon$ is a normally distributed variable with zero mean and unit variance. For dynamic 
welfare analysis, we will need the resilience price information $q(t)$ at any time $t>0$ in addition to that at $t=0$ as derived in (5). Suppose that the system has survived until time $t$ without flipping, then the expected intertemporal welfare at time $t$ becomes

$$
E\left(W_{t}\right)=\int_{t}^{\infty}\left[S\left(X_{t}, s-t\right) U_{1}(s)+F\left(X_{t}, s-t\right) U_{2}(s)\right] \exp [-r(s-t)] d s
$$

where $F\left(X_{t}, s-t\right)=\int_{t}^{s} \theta\left(X_{t}, s\right) /\left[1-F\left(X_{0}, t\right)\right]$ denotes the cumulative flip probability from time $t$ to $s$ conditional on survival up to time $t$. It is readily seen that $F\left(X_{t}, s-t\right)=0$ for $s=t$ and $\lim _{s \rightarrow \infty} F\left(X_{t}, s-t\right)=$ $\int_{t}^{\infty} \theta\left(X_{t}, s\right) /\left[1-F\left(X_{0}, t\right)\right]=1$. Obviously, $S\left(X_{t}, s-t\right)=1-F\left(X_{t}, s-t\right)$ is the probability for the system to survive from $t$ to $s$ conditional on no flips up to timer $t$ (from time 0 ).

Then, the shadow price per unit of the resilience stock $X_{t}$ at time $t$ is defined by

$$
q(t)=\frac{\partial E\left(W_{t}\right)}{\partial X_{t}}=-\int_{t}^{\infty} \frac{\partial F\left(X_{t}, s-t\right)}{\partial X_{t}}\left[U_{1}(s)-U_{2}(s)\right] \exp [-r(s-t)] d s
$$

i.e. the marginal contribution of an extra unit of the resilience stock $X_{t}$ to the expected intertemporal welfare $E\left(W_{t}\right)$, namely, the expected present value of future utilities from time $t$ onwards. As compared with the basic formula in (5), the only difference lies in the conditional flip probability $F\left(X_{t}, s-t\right)$ upon survival at time $t$. For $t=0$, this resilience price formula simply reduces to the basic formula in (5) since the survival probability starting from time 0 and up to time 0 is simply 1.0 !

\section{Comprehensive wealth and genuine saving}

For dynamic welfare analysis, it proves convenient to define the expected wealth at each given date $t$ as a function of the capital stocks including 
the resilience stock ${ }^{4}$ such that $\hat{W}\left(\mathbf{K}_{t}, X_{t}\right)=E\left(W_{t}\right)$ as in (13). Given the autonomous stochastic process in (12), it can be shown that the measure is also autonomous with respect to the "initial" time $t$ as stated in the following lemma:

Lemma 1 Under the assumption of the stochastic process (12), the expected intertemporal welfare $\hat{W}\left(\mathbf{K}_{t}, X_{t}\right)$ is time-autonomous in that $\hat{W}\left(\mathbf{K}_{t}, X_{t}\right)=$ $\hat{W}\left(\mathbf{K}_{t^{\prime}}, X_{t^{\prime}}\right)$ for all $\mathbf{K}_{t}=\mathbf{K}_{t^{\prime}}$ and $X_{t}=X_{t}^{\prime}$ with $t^{\prime} \geq t$.

Proof. For given $X_{t}$ the stochastic process $d X(s-t)$ in (12) is the same as the process $d X\left(s^{\prime}-t^{\prime}\right)$ with $X_{t^{\prime}}=X_{t}$ conditional on the same realization of $d w$. Therefore, $\lambda(s)=\lambda\left(s^{\prime}\right)$ for $s^{\prime}=s+\left(t^{\prime}-t\right)$. This implies that $F\left(X_{t}, s-t\right)=F\left(X_{t^{\prime}}, s^{\prime}-t^{\prime}\right)$ and $S\left(X_{t}, s-t\right)=S\left(X_{t^{\prime}}, s^{\prime}-t^{\prime}\right)$. Moreover, $U_{1}\left(s \mid \mathbf{K}_{t}\right)=U_{1}\left(s^{\prime} \mid \mathbf{K}_{t^{\prime}}\right)$ and $U_{2}\left(s \mid \mathbf{K}_{t}\right)=U_{2}\left(s^{\prime} \mid \mathbf{K}_{t^{\prime}}\right)$ by the invariant utility functional form. Thus, we have

$$
\begin{aligned}
& \hat{W}\left(\mathbf{K}_{t}, X_{t}\right) \\
\equiv & \int_{t}^{\infty}\left[S\left(X_{t}, s-t\right) U_{1}\left(s \mid \mathbf{K}_{t}\right)+F\left(X_{t}, s-t\right) U_{2}\left(s \mid \mathbf{K}_{t}\right)\right] \exp [-r(s-t)] d s \\
& \int_{t^{\prime}}^{\infty}\left[S\left(X_{t^{\prime}}, s^{\prime}-t^{\prime}\right) U_{1}\left(s^{\prime} \mid \mathbf{K}_{t^{\prime}}\right)+F\left(X_{t^{\prime}}, s^{\prime}-t^{\prime}\right) U_{2}\left(s^{\prime} \mid \mathbf{K}_{t^{\prime}}\right)\right] \exp \left[-r\left(s^{\prime}-t^{\prime}\right)\right] d s^{\prime} \\
\equiv & \hat{W}\left(\mathbf{K}_{t^{\prime}}, X_{t^{\prime}}\right)
\end{aligned}
$$

Following Arrow et al. (2003), we are interested in measuring the change in welfare i.e. $d \hat{W}\left(\mathbf{K}_{t}, X_{t}\right)$ over an infinitessimal time interval $[t, t+d t]$. If this change is positive, then dynamic welfare increases over this time interval or we say that the development is sustainable over this interval. With the deterministic model in Arrow et al., this change is simply the genuine saving caused

\footnotetext{
${ }^{4}$ Note that, for notational ease, the expressions $K(t)$ and $X(t)$ will be used interchangably with $K_{t}$ and $X_{t}$, respectively.
} 
by changes in the capital stocks which is the value of capital investment evaluated at the local accounting prices i.e. $d \hat{W}\left(\mathbf{K}_{t}, X_{t}\right)=\mathbf{P}(t) d \mathbf{K}(t)+q(t) d X(t)$ where $\mathbf{P}(t)=\partial \hat{W}\left(\mathbf{K}_{t}, X_{t}\right) / \partial \mathbf{K}_{t}$ is the vector of shadow prices for the conventional capital stocks and $q(t)$ the resilience price at time $t$. For our model with flip uncertainty, however, the problem is more complicated.

First, we need to differentiate between ex-ante and ex-post welfare measures. Suppose that we have come to a date $t+d t$ and learned that no flip has occurred yet, the ex-post change in the expected welfare becomes

$$
d \hat{W} \mid I_{t+d t}=\hat{W}\left(\mathbf{K}_{t+d t}, X_{t+d t}\right)-\hat{W}\left(\mathbf{K}_{t}, X_{t}\right)
$$

If $d \hat{W} \mid I_{t+d t}>0$, the future utility stream as seen from time $t+d t$ onwards has a larger expected present value than that from time $t$. The presumption here is that the system has already safely passed the period of length $d t$ from time $t$ with survival information up to time $t$, i.e. $I_{t+d t}$. However, if we are "standing" at time $t$ before the uncertainty over the following period is resolved, where only the survival information $I_{t}$ at time $t$ is available, then we have two different contingencies at time $t+d t$. If no flip occurs over the period, the intertemporal welfare at $t+d t$ is given by $\hat{W}\left(\mathbf{K}_{t+d t}, X_{t+d t}\right)=$ $E\left(W_{t+d t}\right)$ according to (13). The probability for this event, i.e. the survival probability over $(t, t+d t]$, is $1-\lambda(t) d t$. If a flip would occur, then we have the intertemporal welfare $\bar{W}_{t+d t}=\int_{t+d t}^{\infty} U_{2}(s) \exp (-r(s-t-d t)) d s$, and the probability for such an event is $\lambda(t) d t$.

Note that at time $t$ with survival information $I_{t}$, we are facing at least two important uncertainties: one is the flip uncertainty over the coming period from $t$ to $t+d t$, and the other is the exact realization of the resilience stock $X_{t+d t}$ at time $t+d t$. As seen from time $t$ with survival information up to time $t$, the expected intertemporal welfare at time $t+d t$ can be expressed by

$$
\begin{aligned}
\tilde{E}\left(W_{t+d t}\right) & =(1-\lambda(t) d t) \hat{W}\left(\mathbf{K}_{t+d t}, X_{t+d t}\right)+\lambda(t) d t \bar{W}_{t+d t} \\
& =E_{x}\left[\hat{W}\left(\mathbf{K}_{t+d t}, X_{t+d t}\right)\right]-\lambda(t) d t \Psi_{t+d t}
\end{aligned}
$$


where $\Psi_{t+d t}=E_{x}\left[\hat{W}\left(\mathbf{K}_{t+d t}, X_{t+d t}\right)\right]-\bar{W}_{t+d t}$ denotes the would-be expected loss caused by a certainty flip over $(t, t+d t]$ with respect to the uncertainty in $X_{t+d t}$. From the derived results (15) and (16) above, we now state the ex-ante welfare change according to the proposition

Proposition 2 Conditional on survival information up to time $t$, the expected change in dynamic welfare over an infinitesimal period of time $(t, t+d t)$ is given by

$$
E\left(d \hat{W}_{t} \mid I_{t}\right)=E_{x}\left[\hat{W}\left(\mathbf{K}_{t+d t}, X_{t+d t}\right)-\hat{W}\left(\mathbf{K}_{t}, X_{t}\right)\right]-\lambda(t) \Psi_{t+d t} d t
$$

where the expression in brackets on the right-hand-side denotes the ex-post intertemporal welfare change over the period conditional on survival, and the last term $\lambda(t) \Psi_{t+d t} d t$ is the expected loss due to the flip probability within the period $(t, t+d t)$.

To fix ideas, let us consider an illustrative game of walking on a single-log bridge: anyone who manages to walk through will receive a lottery prize of $\$ 90,100$ and 110 with a chance of $1 / 3$ each. If the player would lose balance, drop into the stream below and end up wet on the other side, he would have to pay a penalty fee of $\$ 900$. The expected ex-ante wealth growth conditional on "no drop" is $E_{x}=\$ 100$ with three possible ex-post rewards $\$ 90,100$ and 110 , and the expected wealth loss becomes $\Psi_{t+d t}=100-(-900)=1000$. While the expected wealth growth for a certain passage would be $\$ 100$, the wealth change for a certain drop would be $E\left(d \hat{W}_{t} \mid I_{t}\right)=100-1000=-900$. For all intermediate cases, the wealth change would depend on the drop probability. $\lambda(t) d t \in(0,1)$. If this probability is 0.05 , then we have $E\left(d \hat{W}_{t} \mid I_{t}\right)=$ $100-0.05 \cdot 1000=\$ 50$. Based on the green net national product $(\mathrm{NNP})$ modelling (cf. Weitzman, 1976; Weitzman, 2001; Aronsson et al., 2004), Tsur and Zemel (2006) has also derived a term similar to $\lambda(t) \Psi_{t+d t} d t$ and used the term to adjust green NNP to conform with the maximum stationary equivalent of future utility. 
Proposition 2 indicates that it is important to distinguish ex-ante and ex-post welfare changes, and in the ex ante case we need to take into account two related but different types of uncertainties - the flip uncertainty over the coming period and the uncertainty of realizations of the resilience stock. Next, we are to Taylor approximate the would-be expected wealth growth $E_{x}\left[\hat{W}\left(\mathbf{K}_{t+d t}, X_{t+d t}\right)-\hat{W}\left(\mathbf{K}_{t}, X_{t}\right)\right]$ conditional on survival. By using lemma 1 together with equation (16) and following Dixit and Pindyck (1994), we derive the following proposition for the expected rate of wealth change:

Proposition 3 Conditional on survival information up to time $t$, the expected rate of change in dynamic welfare is expressed by

$$
\frac{E\left(d \hat{W}_{t} \mid I_{t}\right)}{d t}=\mathbf{P}(t) \dot{\mathbf{K}}(t)+q(t) a(X(t))+\frac{1}{2} \frac{\partial^{2} \hat{W}_{t} \mid I_{t}}{\partial X^{2}(t)} b^{2}(X)-\lambda(t) \Psi_{t+d t}
$$

where $\mathbf{P}(t)=\partial\left(\hat{W}_{t} \mid I_{t}\right) / \partial \mathbf{K}_{t}$ is the accounting price of capital $\mathbf{K}_{t}$, and $a(X(t))=E(d X(t) / d t$ is the expected growth rate in the resilience stock according to (12).

Proof. By equation (12) and lemma 1, the result follows directly from taking a mathematical expectation of a second-order Taylor expansion of the value function. The reason for the third term to appear is that $d X^{2}$ in the generalized Ito process in (12) is of order $d t$ rather than $d t^{2}$ (cf. Dixit and Pindyck, 1994).

While the sum of the first two terms on the right-hand-side of (18) is the expected value of the usual genuine saving, the third term is a loss term due to risk aversion. Suppose that wealth is a concave function of $X_{t}$ such as $\hat{W}_{t}\left(X_{t}\right)=\sqrt{X_{t}}$. For given resilience stock at time $t$ with $X_{t}=100$, we have $\hat{W}_{t}(100)=10$. If the growth in the resilience stock is 0 in the coming period, then wealth growth would be $\sqrt{100}-\sqrt{100}=0$. Now consider a stochastic growth in the resilience stock with $d X=-10$ and $d X=+10$ with $50 \%$ chance each, then the expected growth in wealth would be $\frac{\sqrt{90}+\sqrt{110}}{2}-\sqrt{100} \approx$ 
-0.0126 , which should corresponds to the third term representing loss due to risk aversion. The main point in Proposition 3 is that an ex-ante measure of welfare change should involve two additional loss terms in addition to the expected genuine saving even if the price of the resilience stock is taken into account. Thus, in dynamic welfare analysis with resilience stock and flip uncertainty, we need to be explicit on whether it is an ex-post analysis of welfare change over the "past year" or an expected welfare change over the "coming year".

\section{An extended model with resilience man- agement}

In the above analysis, we have assumed, for simplicity, that the resilience stock is exogenous without any active management. In this section, we show that much of the insights derived from analyzing the basic model carries over to the more general case with resilience management (Carpenter et al., 1999). Suppose that with active resilience management $m(t)$, we can affect the mean and variance of the stochastic process in (12) with resulting values $a^{*}(X, m)$ and $b^{*}(X, m)$, as well as the utility streams $U_{1}^{*}(s)$ and $U_{2}^{*}(s)$ for the non-flipped and flipped case (though capital reallocations), respectively, then resulting cumulative probability function at time $s$ can be written as $F^{*}\left(X_{t, s}-t\right)$, and the corresponding expected wealth function $E\left(W_{t}^{*}\right)$ according to (13). The resilience pricing formula as in (14) becomes

$$
q^{*}(t)=\frac{\partial E\left(W_{t}^{*}\right)}{\partial X_{t}}=-\int_{t}^{\infty} \frac{\partial F^{*}\left(X_{t}, s-t\right)}{\partial X_{t}}\left[U_{1}^{*}(s)-U_{2}^{*}(s)\right] \exp [-r(s-t)] d s
$$

where the time paths for all variables are conditional on the resilience management actions $m(t)$. Unless the flip probability $F^{*}\left(X_{t}, s-t\right)$ over time 
$s \geq t$ can be made to zero by perfect resilience management, the structure of the resilience pricing and sustainability measurement model remains the same though the exact numbers would change.

To eliminate the possibility of any flip risk, it is required that the resiliencerelated stock variable $Z(s)$ to be distributed over some domain $[A, B]$ such that $A>Z_{0}$, i.e. the lower bound of the stock variable should always be greater than the threshold value. For the generalized Ito stochastic process, this is impossible unless there can be unlimited capacity of resilience management for instant adjustment of the stock size. For certain stochastic processes with uniform distributional assumptions, if the management capacity can make the lower bound of the resilience-related stock always above the threshold level, it is of course possible to the eliminate the flip risk completely. In this latter case, the resilience price would be identically zero, and the model collapses to the standard model with no risk of regime shift. However, whether a management program $m(t)$ as such can be justified depends on its benefit and cost via capital reallocations.

\section{Concluding remarks}

This paper is concerned with the theory of ecosystem resilience pricing in the presence of regime shift risks as well as its role for sustainability measurement. In additional to the conventional capital stocks such as natural, physical and human capital, we also consider the variable that affects the resilience of ecosystem functions and stability as a capital stock. Thus, the resilience stock may have a value in its own right even if it may not be directly involved in the production process. In comparison to the other capital forms, this resilience asset enters the model in a different way. Under the normal conditions, it does not matter for the ecosystem services and human well-being. However, when the resilience stock variable crosses a threshold, then the ecosystem will flip into a qualitatively different state (which is termed a regime shift). 
After the flip, the production potential and other intangible services of the system will be rather different and the governing rules for managing the system should also be adapted. If we look at the ex-post outcome, the comprehensive wealth (Arrow et al., 2003) will undergo an abrupt, a noncontinuos fall, at the time when the flip takes place. However, since the flip date in the future is not known with certainty, we also consider of the (ex ante) expected comprehensive wealth as a welfare measure, which is smooth over time. This ex-ante measure involves two additional terms in addition to the standard genuine saving measure: one is the risk aversion loss due to the uncertain realization of the resilience stock and the other is the expected welfare loss due to a possible flip over the period.

The pattern of future flip risks depends on how the resilience stock evolves over time. When the resilience stock is high, e.g. when the biomass of a keystone species is far above its minimum viable population level, we would expect a high probability for the system to remain stable for a given future time horizon. On the contrary, if the system resilience is close to zero, then a small external shock may drive the species into extinction. Thus, the resilience stock has a value per se for its role in retaining ecosystem functioning and stability.

In the basic model, we consider the dynamics of the resilience stock as a pure stochastic process. The shadow price of resilience at any point in time is defined as the present discounted value of future improvements in welfare accrued from the reduced regime flip risk due a unit increase in the concurrent resilience stock. In our extended model, we also allow resilience management which may improve the resilience stock dynamics, and we show that as long as the flip risk cannot be completely eliminated, the qualitative results from the basic model will carry over to the managed ecological-economic system. In this paper, we have not attempted to examine the adaptation strategies but focus on deriving the shadow price of resilience in order to be integrated in social cost-benefit analyses and comprehensive wealth evaluations. 


\section{$7 \quad$ References}

Aronsson T., K.G. Löfgren and K. Backlund (2004), Welfare Measurement in Imperfect Markets - A Growth Theoretical Approach. New Horizons in Environmental Economics, Edward Elgar.

Arrow, K. J., P. Dasgupta, and K.G. Mäler (2003), Evaluating Projects and Assessing Sustainable Development in Imperfect Economies. Environmental and Resource Economics 26, 647-685.

Barbier E. and I. Strand (1998), Valuing mangrove-fishery linkages. Environmental and Resource Economics 12, 151-166

Carpenter S. R, D. Ludwig and W.A., Brock (1999), Management of eutrophication for lakes subject to potentially irreversible change. Ecological Applications 9, 751-771

Cropper, M. L. (1976), Regulating activities with catastrophic effects, Journal of Environmental Economics and Management 3, 1-15.

Dasgupta, P. and K. G. Mäler (2000), Net National Product, Wealth, and Social Well-Being. Environment and Development Economics 5, 69-93.

Dixit, A. K. and R. S. Pindyck (1994), Investment under uncertainty. Princeton University Press, Princeton, NJ.

Ekins P., S. Simon, L. Deutsch, C. Folke, and R. S. de Groot (2003), A framework for the practical application of the concepts of critical natural capital and strong sustainability. Ecological Economics 44, 165-185.

Gunderson, L. H. (2001), Managing Surprising Ecosystems in Southern Florida. Ecological Economics 37, 371-378.

Holling, C.S. (1973), Resilience and stability of ecological systems. Annual Review of Ecology and Systematics 4, 1-23.

Max T., L. Pihl, R. Rönnbäck, H. Wennhage, T. Söderqvist and N. Kautsky (2004), When resilience is undesirable: Regime shifts and ecosystem service generation in Swedish coastal soft bottom habitats. The Beijer Institute of Ecological Economics Discussion Papers 187. 
Mäler K.G., C.Z. Li and G. Destouni (2007), Pricing resilience in a dynamic economy-environment system: a capital theoretical approach. The Beijer Institute of Ecological Economics Discussion Papers 208

Mäler, K.G. (2008), Sustainable Development and Resilience in Ecosystems. Environmental and Resource Economics 1, 17-24.

Nelson D., W.N. Adger and K. Brown (2007), Adaptation to environmental change: Contributions of a resilience framework. The Annual Review of Environmental Resources 32, 395-419.

Norton, B. (1995), Resilience and options, Ecological Economics 15, 133-136.

Pearce W. D., A. Markandya and B. B. Edward (1989), Blueprint for a green economy. Earthscan Ltd, UK

Pearce W. D., G.D. Atkinson (1993), Capital theory and the measurement of sustainable development: an indicator of 'weak' sustainability. Ecological Economics 8, 103-108

Perrings, C. (2006), Resilience and sustainable development. Resource and Development Economics 11, 417-427.

Samuelson P.A. (1961), The evaluation of "social income: capital formation and wealth. In: Lutz F.A., Hague D.C. (eds) The theory of capital. Macmillan, London.

Scheffer, M., S. R. Carpenter, J. A. Foley, C. Folke, and B. Walker (2001), Catastrophic shifts in ecosystems. Nature 413, 591-596.

Tsur, Y. and A. Zemel (2006), Welfare Measurement under Threats of Environmental Catastrophes. Journal of Environmental Economics and Management 52, 421-429.

Weitzman, M.L. (1976), On the Welfare Significance of National Product in a Dynamic Economy. Quarterly Journal of Economics 90, 156-162.

Weitzman, M.L. (2001), A Contribution to the Theory of Welfare Accounting. Scandinavian Journal of Economics 103, 1-24.

Walker B, L. Pearson, M. Harris, K.G. Mäler, C.Z. Li, R. Biggs (2010), Incorporating resilience in the assessment of inclusive wealth: an example 
from South East Australia. Environmental and Resource Economics 45, 183-202. 
WORKING PAPERS*

Editor: Nils Gottfries

2009:7 Tobias Lindhe and Jan Södersten, Dividend taxation, share repurchases and the equity trap. $27 \mathrm{pp}$.

2009:8 Che-Yuan Liang, Nonparametric Structural Estimation of Labor Supply in the Presence of Censoring. 48pp.

2009:9 Bertil Holmlund, Incentives in Business and Academia. 12pp.

2009:10 Jakob Winstrand, The Effects of a Refinery on Property Values - The Case of Sweden. 27pp.

2009:11 Ranjula Bali Swain and Adel Varghese, The Impact of Skill Development and Human Capital Training on Self Help Groups. 28pp.

2009:12 Mikael Elinder. Correcting Mistakes: Cognitive Dissonance and Political Attitudes in Sweden and the United States. 25 pp.

2009:13 Sören Blomquist, Vidar Christiansen and Luca Micheletto: Public Provision of Private Goods and Nondistortionary Marginal Tax Rates: Some further Results. 41pp.

2009:14 Mattias Nordin, The effect of information on voting behavior. 34pp.

2009:15 Anders Klevmarken, Olle Grünewald and Henrik Allansson, A new consumer price index that incorporates housing. 27 pp.

2009:16 Heléne L. Nilsson, How Local are Local Governments? Heterogeneous Effects of Intergovernmental Grants. 41pp.

2009:17 Olof Åslund, Per-Anders Edin, Peter Fredriksson and Hans Grönqvist, Peers, neighborhoods and immigrant student achievement - evidence from a placement policy. $27 \mathrm{pp}$.

2009:18 Yunus Aksoy, Henrique S. Basso and Javier Coto-Martinez, Lending Relationships and Monetary Policy. 42 pp.

2009:19 Johan Söderberg, Non-uniform staggered prices and output persistence. $38 \mathrm{pp}$.

2010:1 Jonathan Gemus, College Achievement and Earnings. 43 pp.

2010:2 Susanne Ek and Bertil Holmlund, Family Job Search, Wage Bargaining, and Optimal Unemployment Insurance. 30 pp.

2010:3 Sören Blomquist and Laurent Simula, Marginal Deadweight Loss when the Income Tax is Nonlinear. 21 pp.

\footnotetext{
* A list of papers in this series from earlier years will be sent on request by the department.
} 
2010:4 Niklas Bengtsson, The marginal propensity to earn, consume and save out of unearned income in South Africa. 34 pp.

2010:5 Marcus Eliason and Henry Ohlsson, Timing of death and the repeal of the Swedish inheritance tax. $29 \mathrm{pp}$.

2010:6 Teodora Borota, Innovation and Imitation in a Model of North-South Trade. $44 \mathrm{pp}$.

2010:7 Cristiana Benedetti Fasil and Teodora Borota, World Trade Patterns and Prices: The Role of Productivity and Quality Heterogeneity. 24 pp.

2010:8 Johanna Rickne, Gender, Wages and Social Security in China’s Industrial Sector. 48 pp.

2010:9 Ulrika Vikman, Does Providing Childcare to Unemployed Affect Unemployment Duration? 43 pp.

2010:10 Sara Pinoli, Rational Expectations and the Puzzling No-Effect of the Minimum Wage. 56 pp.

2010:11 Anna Persson and Ulrika Vikman, Dynamic effects of mandatory activation of welfare participants. $37 \mathrm{pp}$.

2010:12 Per Engström, Bling Bling Taxation and the Fiscal Virtues of Hip Hop. $12 \mathrm{pp}$.

2010:13 Niclas Berggren and Mikael Elinder, Is tolerance good or bad for growth? $34 \mathrm{pp}$.

2010:14 Magnus Gustavsson and Pär Österholm, Labor-Force Participation Rates and the Informational Value of Unemployment Rates: Evidence from Disaggregated US Data. 10 pp.

2010:15 Chuan-Zhong Li and Karl-Gustaf Löfgren, Dynamic cost-bene $t$ analysis of large projects: The role of capital cost. 8 pp.

2010:16 Karl-Göran Mäler and Chuan-Zhong Li, Measuring sustainability under regime shift uncertainty: A resilience pricing approach. 20 pp.

See also working papers published by the Office of Labour Market Policy Evaluation http://www.ifau.se/ 